\title{
Distributed governance of Solar Radiation Management geoengineering: A possible solution to SRM's "free-driver" problem?
}

(C) The Author(s) 2019. This article is published with open access at link.springer.com and journal.hep.com.cn

\begin{abstract}
Geoengineering (deliberate climate modification) is a possible way to limit Anthropogenic Global Warming (AGW) (Shepherd, 2009; National Research Council, 2015). Solar Radiation Management geoengineering (SRM) offers relatively inexpensive, rapid temperature control. However, this low cost leads to a risk of controversial unilateral intervention-the "free-driver" problem (Weitzman, 2015). Consequently, this creates a risk of counter-geoengineering (deliberate warming) (Parker et al., 2018), resulting in governance challenges (Svoboda, 2017) akin to an arms race. Free-driver deployment scenarios previously considered include the rogue state, Greenfinger (Bodansky, 2013), or power blocs (Ricke et al., 2013), implying disagreement and conflict. We propose a novel distributed governance model of consensually-constrained unilateralism: Countries' authority is limited to each state's fraction of the maximum realistic intervention (e.g., pre-industrial temperature). We suggest a division of authority based on historical emissions (Rocha et al., 2015) — noting alternatives (e.g., population). To aid understanding, we offer an analogue: An over-heated train carriage, with passenger-controlled windows. We subsequently discuss the likely complexities, notably Coasian side-payments. Finally, we suggest further research: Algebraic, bot and human modeling; and observational studies.
\end{abstract}

Keywords geoengineering, Solar Radiation Management, governance, decentralised

Received December 26, 2018; accepted June 4, 2019

Andrew LOCKLEY ( $₫)$

Bartlett School of Construction and Project Management, University College London, 1-19 Torrington Place, London WC1E 7HB, UK

E-mail: andrew.lockley@gmail.com

\section{Introduction}

Climate change (Intergovernmental Panel on Climate Change (IPCC), 2013) is a critical issue for humanity, in coming centuries. Globally-significant expenditure is required to address resulting geophysical, political and societal changes (Stern, 2006). Considerable international and domestic negotiating efforts have been made to forge the agreements (Framework Convention on Climate Change (FCCC), 2014) necessary to constrain expected temperature rises. Challenges in successfully and rapidly transforming global energy systems (to decouple energy production from $\mathrm{CO}_{2}$ emissions) have triggered a revival of geoengineering discussions - as an alternative or (more credibly) a supplement to adaptation and mitigation. Ordinarily, geoengineering is now interpreted as the deliberate modification of the climate system.

Two principal strands exist (Shepherd, 2009):

(1) CDR: Carbon Dioxide Removal, or (more generally) Greenhouse Gas Removal (GGR) (Lomax et al., 2015), seeks to solve the fundamental problem of Anthropogenic Global Warming (AGW), by removing atmospheric greenhouse gases (GHGs). To clarify: GGR additionally includes removal of secondary GHGs (methane, etc.). The slow-acting, well-distributed and expensive nature of CDR/GGR means near-term governance challenges are modest, save for process externalities (e.g., land take, in the case of afforestation). This is because no single actor (not even a powerful state) can unilaterally, rapidly, and controversially reduce global temperatures with CDR. For clarity, CDR is not the subject of this paper and this brief introduction is for background only.

(2) SRM: Solar Radiation Management effects changes to Earth's radiation balance, ordinarily by reflecting sunlight. SRM proposals include: Marine Cloud Brightening (MCB), and Stratospheric Aerosol Injection (SAI). SRM offers an incomplete solution to emissions - being both temporary and imperfect in its corrections (e.g., 
leading to reduced precipitation, relative to a world with neither AGW nor SRM). SRM is comparatively fast-acting and inexpensive, as well as uneven in the global distribution of its effects - thus posing significant governance challenges (Svoboda, 2017) due to its low cost causing a free-driver problem (Weitzman, 2015). N.B.: The body of this paper uses "geoengineering" to refer to SRM geoengineering (except where otherwise specified), as governing SRM is its principle subject.

A plain-English summary of SAI, the leading SRM technology, is as follows:

Specialised jet aircraft would spray sulphuric acid into the stratosphere, well above the operational ceiling of civilian aircraft. Here, the acid would form a stable haze - loosely akin to thin, high cloud (albeit far above ordinary clouds). This would serve to reflect an amount of sunlight to space - sufficient to reduce future temperature increases from global warming, or to reverse historic rises. This sulphur-injection process is well-tested by volcanoes, which offer a close natural analogue.

Generally, large-scale geoengineering has not yet occurred, excepting afforestation, etc. Additionally, various enabling technologies remain theoretical - although CDR and SRM are generally regarded as technically feasible. For CDR, cost and scale remain major barriers. SRM's geophysical risk and controversial nature underpin current deployment reticence.

Geoengineering (both SRM and CDR) increasingly influences both academic and general climate discourses. CDR influences international treaties and national policies. The recent Paris Agreement envisages CDR at scale during $2050-2100$ (Lewis, 2015). SRM is not currently widely accepted as a policy instrument, although a growing body of academic and policy literature on the subject of SRM governance shows that significant work is being done to create a governance framework for both deployment and experimentation (Chhetri et al., 2018).

Geoengineering joins mitigation and adaptation, constituting the three potential strands of climate policy (Brown, 2010) - and a brief discussion of their interrelation is merited. SRM is often seen as a considerably cheaper alternative to mitigation (Freakonomics (Levitt and Dubner, 2005) makes this case to a general audience). This "alternative" framing can be found in general political discourse - seemingly appealing especially to conservatives - as a means to avoid the economic disruption of modifying the global energy system (Appell, 2013). This restricted economic framing of AGW (and consequential SRM response) lacks scientific credibility. Using SRM as a "get out of jail free card" to avoid reorganisation of the world's energy system is refuted as a policy option by scientifically-credible commentators (Intergovernmental Panel on Climate Change (IPCC), 2014). The potential for a mitigation/geoengineering trade-off has been widely discussed - but a dichotomous-choice framing is not only inappropriate, it has also been overtaken by history (due to rapid renewables expansion) (Randall, 2015). Conversely, adaptation is not ordinarily presented as an alternative to geoengineering - yet SRM deployment would necessarily affects adaptation's necessity, costs, range and scale. AGW adaptation takes various forms, countering AGW's multifaceted effect. Accordingly, costs vary widely - yet are large in totality (Stern, 2006).

As SRM is ordinarily advocated by experts as a complement to mitigation (not as a replacement to it, in whole or major part), a comprehensive treatment of possible interactions between mitigation, adaptation and SRM geoengineering is therefore not relevant to the core discussion. Other authors offer a fuller treatment of this overlap (Gordijn and Ten Have, 2012; Brasseur and Granier, 2013).

\section{Discussions}

We note the challenges of governing geoengineering. Whilst there are complexities to monitoring and control of the process details, the issue at large scale can be simply summarised as, "Who controls the thermostat?"

Authors (Ricke et al., 2013) previously discussed have offered analysis of the potential for the formation of power blocs - so there is not necessarily a singular "who" in this situation. Additionally, there is potential capacity for clandestine operations - meaning that the "who" may be unidentified (Lockley, 2016a). Finally, SRM control is not a one-way process, with counter-geoengineering postulated (Parker et al., 2018).

Accordingly, there is a need to consider governance models that reduce the capacity for the strong to override the weak, or for a covert/rogue operator to undermine the consensus strategy. To this end, we propose a new governance model, based on constrained unilateralism.

Simply put, countries would agree a maximum conceivable geoengineering intervention (likely a return to pre-industrial temperatures). This maximum intervention would then be divided up among countries, such as by their share of historic carbon emissions (or by population, land area, etc.). Each country would be free to conduct geoengineering (directly, or by proxy) up to their allocated maximum intervention. For example, if global warming was $2^{\circ} \mathrm{C}$, and the US was responsible for a quarter of global historic emissions, then it could unilaterally reduce global temperature by $0-0.5^{\circ} \mathrm{C}$. For clarification: It is assumed that all interventions would be public, allowing countries to react to others' policy changes.

To aid discussion, we consider a real-world analogue: A naturally-ventilated railway carriage, with passenger-controlled windows. We constrain this model, offering the following features:

a) The railway carriage is internally open. Passengers sit in a single compartment. The carriage is sealed from other carriages in the train. 
b) The carriage is constantly and evenly heated - by sunlight, fixed-output heating, etc.

c) Air in the carriage is well-mixed, meaning there are no hot spots or cold spots.

d) Passengers sit on bench seats along the sides of the carriage, with their backs to the windows (a format common on various London Underground trains). There are no standing passengers, nor does anyone lack access to a window.

e) Behind each seat is a small window, which opens to the outside air. (For simplicity, we assume that each window allows the same volume of cold outside air to enter, regardless of the status of any other window.)

f) Windows open by sliding, and are therefore able to adopt infinitely many intermediate positions.

g) Many seats are unoccupied. It is assumed that passengers can control windows on adjacent, unoccupied seats - up to halfway to the next passenger. (For simplicity, we assume that passengers do not attempt to control any windows that are equidistant between themselves and another passenger.) This allocates each passenger a "territory" of varying size - loosely analogous to countries of varying sizes. As discussed previously, this size may usefully be constrained by historic emissions, population, etc., as opposed to land area.

h) The passengers are heterogeneous in terms of the temperature preferences and willingness to intervene, and these internal policies may change arbitrarily.

i) All passengers' windows are visible to each other at all times.

j) A non-zero effort is required to adjust a window, thus deterring small interventions.

This idealized analogous system offers a possible model for international action on geoengineering, with the following shared features:

a) "Countries" of differing sizes (by historical emissions).

b) "Countries" with differing temperature preferences and action thresholds. For example: Country A may prefer pre-industrial temperatures, but will only start to deploy SRM at $4^{\circ} \mathrm{C}$; Country B may prefer $1{ }^{\circ} \mathrm{C}$ of warming, but may deploy SRM at $2^{\circ} \mathrm{C}$. (Notably, the temperature threshold to start SRM may differ from the temperature at which deployment is stopped.)

We, therefore, add an entirely new model to previous discussions of governance: That of limited unilateral control. Notably, this differs from democracy or negotiation, in that there is no central authority or forum for determining policy - by contrast, policy is emergent.

There is no need for any country to state a temperature preference, or even establish one in advance - it only need act if it decides that a threshold for action is crossed. Countries' temperature preferences and action thresholds may vary at any time - although the overhead of effecting policy change acts to deter erratic behaviour, or the setting of an impractically-narrow temperature band. Reputational effects will also tend to favour stability; countries generally wish to avoid being perceived as having erratic policies.

An informal literature search has not revealed any detailed studies of temperature control on trains with manual windows - either thermodynamic, or sociological. However, from observation and anecdote, we note that the temperature of trains is normally maintained at a broadly stable and comfortable level, and that conflict amongst passengers during this process is exceedingly rare.

The key assumption constraining this model (derived from casual observations of emergent behaviour) is that train passengers do not, in typical circumstances, attempt to open windows substantially beyond their own seat. Situations are rarely (if ever) observed where passengers forcibly control windows in others' "territory". Simply put, an emergent system of distributed temperature control arises, without the external imposition of any system of rules. Should equivalent norms be replicable in the field of SRM governance, it offers hope for stable and consensusbased intervention.

However, real-world behaviour is not as rigidly constrained as described above. Passengers may lobby near neighbours, by asking permission to open nearby windows. An analogue for this rights-exchange phenomenon (applicable within an SRM context) is the potential for Coasian side payments, with deals between interfering radio stations being a classic example (Coase, 1960). While train passengers do not typically make explicit side payments, they do often willingly give up control. This delegation of decision making, and the associated costs of intervention, is equivalent to a side payment in kind - by means of labour provision. This creates a local free-rider situation, as opposed to a free-driver. Any side-payments for undesirable over-cooling may take the form of goodwill - in the same way that countries may allow sharing of transit corridors, disaster response capacity, etc., without overt payment.

How, then, could this train model be practically-applied to global SRM policy? The framework described above may be implemented in a remarkably simple fashion: A maximum conceivable temperature reduction would be agreed, then the commensurate SRM allocation would be shared by a chosen method (e.g., by population). Crucially, this maximum reduction is not a consensus or target temperature; it is a temperature below which any reduction is agreed to be dangerous or unjustified. This maximum cooling may be down to pre-industrial temperature (although, conceivably, other limits could be proposed). After total maximum cooling is limited in this way, each nation would be allocated proportional authority to intervene. We anticipate this would be allocated by historical emissions - although GDP, population, or land area could conceivably be used.

The measures used for SRM allocations are intended to be dynamic. For example, changing population levels 
would attract a new allocation - although these adjustments would ordinarily be gradual enough to effect only limited change, even on countries using their full cooling allowance. Using slow-changing variables (land area or population) to control SRM allocation reduces the influence of perverse incentives or moral hazard (Lockley and Coffman, 2016), which may conceivably exist if allocations are based on rapidly-varying factors, such as current emissions.

Once each country had been allocated its SRM allowance, this allocation could be then used, withheld, or distributed, as each country may see fit. Countries may, in turn, seek to delegate control to states or provinces, using whatever method of allocation they see fit. Similarly, they may concede control to neighbours or allies - just as train passengers may allow nearby passengers to control their windows.

A country preferring a warmer world (perhaps Russia) could hold its permits, preventing geoengineering on its share. A country preferring a cooler world (perhaps Tuvalu) would be free to geoengineer directly, or to pay a firm or third country to deploy its allocation. Should any country decide (for whatever reason) not to take part in the process, it could volunteer to reallocate its permits to other countries-perhaps in proportion to these remaining countries' existing allocations, or alternatively by a grant to a technocratic leader. By this method, such countries would volunteer to become passengers in the temperaturesetting process. A variety of reasons for such an abdication are conceivable: Political instability; lack of scientific capability; internal tensions; conscientious objection; or a wish to avoid exposure to lobbying or coercion. An indolent or indifferent country (especially a large one), should it find itself with unused permits essential to deliver the "last mile" of cooling, may face widespread lobbying (or payment) to deploy or surrender its permits. Any mass movement towards abdication and surrender may serve to destabilize the system, placing disproportionate power in the hands of remaining participant states. This may engender a situation where the climate is rendered vulnerable to unpredictable changes in the political landscape of key states, were they to hold a large fraction of actionable permits. Such a situation would remove the stabilizing effect of a multipolar decision-making process, so caps on reallocation or surrender may be made. Enforcing limits on surrender would be difficult, with obvious challenges in controlling side-bargains enacted to disempower weaker states.

One possible complication is that permits could conceivably be openly or covertly sold in a purelyeconomic transaction - a Coasian side payment, discussed previously. Even if direct sale was prohibited, there is no credible way to prevent negotiations over permits being woven into the wider international negotiation process. Apparently-unrelated aspects of international relations would form an inevitable political background to geoengineering discussions. Conceivable conversations may proceed as follows: "Ambassador, your country's delay in forming a workable policy on geoengineering is making our citizens reluctant to support the additional infrastructure investment you seek." Equivalent Coasian payments are not normally observed on trains (e.g., nobody offers coffee or cash to persuade others to open windows). However, a range of social constraints may exist on such behaviours, although these differ between our model and reality. Normally, modern states have a range of inviolate principles. These are not broken, even in the presence of substantial incentives. For example, significant territory is rarely exchanged commercially between states in modern times, nor do states ordinarily surrender citizens (save wanted criminals). Making or accepting such offers is essentially taboo - an indecent proposal, and one which cannot be accepted without disproportionate loss of status. Whether comparablyrestrictive norms could be established for the proposed SRM governance system is moot. Potentially, a more viable system of norms may be that any such side payments are made transparently, and placed on public record.

An overt Coasian system risks concentration of SRM capacity in the hands of affluent states. Nevertheless, the use of a market model for distribution of permits would not necessarily be harmful. Countries could conceivably trade their permits to offset losses of income or utility — such as a loss of tourist revenue, or agricultural productivity (Coase, 1960). Accordingly, trading of such permits may be beneficial, as it would potentially allow more economically-efficient outcomes to arise - as described for other markets in which Coasian side-payments operate (e.g., radio interference). Further, richer countries tend to have more stable, competent bureaucracies and greater scientific capabilities, which may aid well-managed, consistent and responsible deployment.

One geophysical issue left unaddressed directly is the issue of termination shock. This refers to sudden, harmful warming, resulting from the withdrawal of geoengineering (Shepherd, 2009). While the model proposed does not offer specific protections, the inherent stability of the distributed, democratic system envisaged tends to reduce the risk of dangerous adjustments to the temperature. This stabilisation is achieved by two mechanisms. Firstly, a limitation of centralised capacity. Secondly, the ability of other states to expand geoengineering in response to a sudden, unsafe cut in cooling by any state.

Notwithstanding the above, a specific regulatory agreement may be reached for this particular purpose - perhaps mandating a limited speed of reduction in any commenced geoengineering intervention. As discussed above, any large-scale surrender of rights under this scheme will tend to reduce its capacity to function as a coherent system albeit a distributed one. Opt-out by smaller, less advanced countries (e.g., Ghana) may be seen as reasonable or 
inevitable. However, if large states (e.g., India), or multistate bodies (such as the EU) were to opt-out, the system may be destabilised. To prevent this, setting limits on repooling of allocation may be desirable. For example, pooling for more than one year in advance may be prohibited. Alternatively, a pool cap of $25 \%$ of the total allocation may be made.

The proposed methodology is concerned with overarching strategy, not the minutiae of implementation. Inevitably, any such high-level proposal opens a Pandora's Box of downstream issues. These principally pertain to the practical challenge of ensuring an effective meshing of different national policies and operations. Additionally, there is a need to control issues arising from clandestine or otherwise non-permitted operations, or undue influence. The multi-agent nature of the limited unilateral model proposed means that the need for vigilant management is arguably enhanced, compared to, e.g., a benign hegemonic deployment. To avoid covering aspects of the discussion already dealt with in depth by other authors, the reader's attention is directed to papers dealing firstly with appropriate oversight and coordination of multi-party operations (Lockley, 2016b), and secondly with the challenges and risks posed by clandestine SRM deployment (Lockley, 2016a).

\section{Conclusions}

Extant SRM governance analysis generally assumes unlimited potential scale for any one country's SRM intervention. This may be regarded as an unconstrained free-driver model. Whilst such a free-for-all may be a technically-feasible structure for control, it does not represent the only viable model-nor necessarily the optimal one. Awareness of free-driver risks may serve to force the international community to create a viable and agreed governance framework.

We present an alternative governance model, based on amending the one key assumption of unlimited intervention capacity. By imposing a country-by-country scale limitation, we adopt a limited free-driver model. We assume that the sum of all limits is the maximum reasonable intervention desired-which, as a working assumption, we take to be pre-industrial. Otherwise, the proposed model lacks any additional controls - save a requirement for transparency, and a possible protocol to govern sale or surrender of distributed permits. Notably, we omit any compensatory regime, although anticipated Coasian side-payments may fulfil a similar function (this detail is an important area for further investigation). We propose the intervention ceiling for each nation be set by its proportion of global historic emissions. This slowchanging metric avoids the risk of gaming (which may affect more volatile measures), and it benefits from an obvious link to climate. Nevertheless, we note that other measures, e.g., population, may be preferable, for various reasons.

We informally compare our proposed structure to casually-observed behaviour in train carriages. This loose analogue to our proposed governance model has been deemed viable by train operators for many decades, only falling out of regular use with the advent of air conditioning. We note additionally the lack of any externally-imposed systems of rules, staff interventions, or other such centralised governance. Despite this informality, we note that the system operates broadly successfully in real-world conditions.

Accordingly, we suggest that comparable distributedgovernance systems may offer political and social stability - perhaps beyond that offered by other, previously-proposed models. We note that our analogous hot train behavioural model arises spontaneously, and therefore argue that similar geoengineering governance norms may also arise spontaneously - potentially persisting, even in the absence of formal governance.

Accordingly, we suggest the following avenues for future research:

1) Algebraic modelling of agent behaviour in distributed-governance systems, with realistic parameters derived from climate and SRM policy preferences.

2) Multi-agent simulation of the proposed model, using bots or humans.

3) Audit of train carriage design and accompanying rules in different locations and cultures, together with studies of human behaviour within them.

4) Identification of other analogous systems.

5) Mapping the essential features of train and other successful distributed-governance systems onto SRM control frameworks.

Open Access This article is licensed under a Creative Commons Attribution 4.0 International License, which permits use, sharing, adaptation, distribution and reproduction in any medium or format, as long as you give appropriate credit to the original author(s) and the source, provide a link to the Creative Commons licence, and indicate if changes were made.

The images or other third party material in this article are included in the article's Creative Commons licence, unless indicated otherwise in a credit line to the material. If material is not included in the article's Creative Commons licence and your intended use is not permitted by statutory regulation or exceeds the permitted use, you will need to obtain permission directly from the copyright holder. To view a copy of this licence, visit http:/ creativecommons.org/licenses/by/4.0/.

\section{References}

Appell D (2013). Strange bedfellows? Climate change denial and support for geoengineering. Yale Forum on Climate Change $\&$ the Media, October 30. Available at: www.yaleclimateconnections.org/ 2013/10/

Bodansky D (2013). The who, what, and wherefore of geoengineering governance. Climatic Change, 121(3): 539-551 
Brasseur G P, Granier C (2013). Mitigation, adaptation or climate engineering? Theoretical Inquiries in Law, 14(1): 1-20

Brown M A (2010). Policy update: The multiple policy dimensions of carbon management: Mitigation, adaptation and geoengineering. Carbon Management, 1(1): 27-33

Chhetri N, Chong D, Conca K, Falk R, Gillespie A, Gupta A, Jinnsh S, Kashwan P, Lahsen M, Light A, McKinnon C, Thiele L P, Valdivia W, Wapner P, Morrow D, Turkaly C, Nicholson S (2018). Governing Solar Radiation Management. Washington DC: Forum for Climate Engineering Assessment, American University

Coase R H (1960). The problem of social cost. Journal of Law \& Economics, 3: 1-44

Framework Convention on Climate Change (FCCC) (2014). Report of the conference of the parties on its twentieth session, held in Lima from 1 to 14 December 2014. FCCC, United Nations. Available at: www.ctc-n.org/file/109

Gordijn B, Ten Have H (2012). Ethics of mitigation, adaptation and geoengineering. Medicine, Health Care, and Philosophy, 15(1): $1-2$

Intergovernmental Panel on Climate Change (IPCC) (2013). Summary for policymakers. In: Climate Change 2013: The Physical Science Basis, Contribution of Working Group I to the IPCC's Fifth Assessment Report. Cambridge, UK: Cambridge University Press, $1-30$

Intergovernmental Panel on Climate Change (IPCC) (2014). Climate Change 2014: Mitigation of Climate Change, Contribution of Working Group III to the IPCC's Fifth Assessment Report. Cambridge, United Kingdom and New York, NY, USA: Cambridge University Press

Levitt S D, Dubner S J (2005). Freakonomics. New York: William Morrow

Lewis S (2015). The dirty secret of the Paris climate deal. Foreign Policy. Available at: foreignpolicy.com/2015/12/17/

Lockley A (2016a). Geoengineering: A war on climate change? Journal of Evolution and Technology, 26(1): 26-49
Lockley A (2016b). Licence to chill: Building a legitimate authorisation process for commercial SRM operations. Environmental Law Review, 18(1): 25-40

Lockley A, Coffman D (2016). Distinguishing morale hazard from moral hazard in geoengineering. Environmental Law Review, 18(3): 194204

Lomax G, Workman M, Lenton T, Shah N (2015). Reframing the policy approach to greenhouse gas removal technologies. Energy Policy, 78: 125-136

National Research Council (2015). Climate Intervention: Reflecting Sunlight to Cool Earth. Washington DC: The National Academies Press

Parker A, Horton J B, Keith D W (2018). Stopping solar geoengineering through technical means: A preliminary assessment of countergeoengineering. Earth's Future, 6(8): 1058-1065

Randall T (2015). Fossil fuels just lost the race against renewables. Available at: www.bloomberg.com/news/articles/2015-04-14/

Ricke K L, Moreno-Cruz J B, Caldeira K (2013). Strategic incentives for climate geoengineering coalitions to exclude broad participation. Environmental Research Letters, 8(1): 014021

Rocha M, Krapp M, Guetschow J, Jeffery L, Hare B, Schaeffer M (2015). Historical responsibility for climate change - from countries emissions to contribution to temperature increase. Potsdam, Germany: Climate Analytics and Potsdam Institute for Climate Impact Research. Available at: climateanalytics.org/publications/ 2015/

Shepherd J G (2009). Geoengineering the Climate: Science, Governance and Uncertainty. London: The Royal Society

Stern N H (2006). The Economics of Climate Change: The Stern Review. London: Cambridge University Press

Svoboda T (2017). The Ethics of Climate Engineering: Solar Radiation Management and Non-Ideal Justice. New York: Routledge

Weitzman M L (2015). A voting architecture for the governance of freedriver externalities, with application to geoengineering. Scandinavian Journal of Economics, 117(4): 1049-1068 